\title{
LA DOLARIZACIÓN FINANCIERA: EXPERIENCIA INTERNACIONAL Y PERSPECTIVAS PARA COLOMBIA
}

\author{
Carlos E. León Rincón* \\ Alejandro Revéiz Herault**
}

$\mathrm{L}$ a dolarización financiera, que permite que el público haga depósitos y adquiera obligaciones en moneda extranjera, es un hecho común en países y regiones en desarrollo, como América Latina. Colombia hoy tiene un bajo nivel de dolarización financiera, debido principalmente a que no está permitida por la legislación financiera.

Este trabajo analiza desde el punto de vista económico y financiero si se justifica la dolarización financiera en Colombia, y las implicaciones de su adopción. Primero muestra qué es la dolarización, su tipología y sus características. Luego examina la dolarización financiera, hace una revisión teórica de sus causas, muestra evidencia empírica de varios países latinoamericanos y revisa sus principales efectos. En el marco de la situación actual de la economía, la penúltima sección hace algunas consideraciones sobre el caso colombiano, La última sección presenta las conclusiones. El anexo sintetiza la experiencia de Chile y Perú.

\footnotetext{
* Magíster en Banca y Finanzas, profesional experto en apoyo de liquidez y control de riesgos del Departamento de Operaciones y Desarrollo de Mercados de la Subgerencia Monetaria y de Reservas del Banco de la República, Bogotá, Colombia, [cleonrin@banrep.gov.co].

** Doctor en Economía Financiera, investigador principal de la Subgerencia Monetaria y de Reservas, Bogotá, Colombia, [areveihe@banrep.gov.co]. Este trabajo no compromete al Banco de la República ni a su Junta Directiva. Las opiniones expresadas y cualquier error u omisión son responsabilidad de los autores. El documento se enriqueció con los comentarios de Leonardo Villar, Juan J. Echavarría, José D. Uribe, Fernando Tenjo, Juan M. Laserna, Carlos G. Cano, Hernando Vargas, José Tolosa, Jorge Toro y Clara L. Machado. Fecha de recepción: 1 de febrero de 2008, fecha de modificación: 17 de marzo de 2008, fecha de aceptación: 6 de mayo de 2008.
} 


\section{LA DOLARIZACIÓN}

En general, la dolarización es la utilización de una moneda extranjera, usualmente el dólar de Estados Unidos ${ }^{1}$, en vez de la moneda local, en nuestro caso, el peso.

En términos más específicos, la dolarización es la adopción de una moneda extranjera para que cumpla alguna o todas las funciones de la moneda local, a saber: medio de pago, unidad de cuenta y reserva de valor. Y se la puede clasificar entonces como indica el cuadro 1.

Cuadro 1

Clases y tipos de dolarización

\begin{tabular}{llll}
\hline \multirow{3}{*}{ Parcial } & De pagos & Uso del dólar como medio de pago & Medio de pago \\
\cline { 2 - 4 } & Real & Indexación de precios & Unidad de cuenta \\
\cline { 2 - 4 } & Financiera & Uso del dólar para denominar activos y pasivos & Reserva de valor \\
\hline Total & & Reemplazo total de la moneda local & Todas las anteriores \\
\hline
\end{tabular}

Con la dolarización total, el dólar es de curso legal y forzoso, y asume todas las funciones mencionadas, como en El Salvador, Ecuador y Panamá. Esa decisión se justifica en diversas circunstancias (Sachs y Larrain, 1999): i) economías muy integradas con el emisor de moneda extranjera que, por ende, experimentan ciclos económicos muy similares; ii) economías pequeñas cuyos precios ya están denominados en moneda extranjera y en que la mayor parte de los productos se comercia con el exterior; iii) países con mercados laborales muy flexibles, donde los ajustes nominales se pueden realizar vía costos laborales y aumento de la productividad, y iv) países donde la política monetaria no es creíble.

Como muestra el cuadro 2, el número de países o territorios independientes que están dolarizados totalmente es bajo y poco representativo $^{2}$; Ecuador es el más grande en términos de población y PIB, seguido de El Salvador y Panamá.

Por otra parte, la dolarización parcial, bien sea de pagos, real o financiera, es muy común en las regiones en desarrollo, incluida América Latina.

\footnotetext{
${ }^{1}$ En este trabajo se usará el dólar de Estados Unidos como moneda extranjera y el peso como moneda local.

${ }^{2}$ La población que vive en países o territorios independientes con dolarización total apenas llega al 0,39\% del total mundial y al 57,51\% de la población colombiana; el PIB de estos países es inferior al 0,0\% del PIB mundial, el 119,9\% del PIB de Colombia.
} 
La dolarización de pagos o sustitución monetaria, en la que los residentes utilizan el dólar como medio de pago, responde a la desconfianza del público en su moneda para realizar transacciones cotidianas, la que puede lleva a sustituirla por otra moneda o medio de pago que el público estime más conveniente. La desconfianza puede obedecer, por ejemplo, a un alto nivel de inflación que penaliza la tenencia de moneda local (Ize y Parrado, 2002, y De Nicoló et al., 2003); este fue el caso de la economía ecuatoriana antes de la dolarización total, cuando los agentes económicos sustituyeron el sucre por el dólar en sus transacciones (Sierra y Padilla, 2000).

Cuadro 2

Países independientes con dolarización oficial total, $2007^{3}$

Miles de millones de dólares de Estados Unidos

\begin{tabular}{lllll}
\hline País o territorio & Habitantes & PIB & Moneda & Desde \\
\hline Andorra* & 71.822 & 2,77 & Euro & 1278 \\
Mónaco* & 32.671 & 0,99 & Euro & 1865 \\
Tuvalu & 11.992 & 0,02 & Dólar de Australia & 1892 \\
San Marino & 29.615 & 0,85 & Euro & 1897 \\
Panamá & 3.242 .173 & 25,29 & Dólar de EEUU y balboa & 1904 \\
Nauru* & 13.528 & 0,06 & Dólar de Australia & 1914 \\
Liechtenstein & 34.247 & 1,78 & Franco de Suiza & 1921 \\
Ciudad del Vaticano & 821 & N/D & Euro & 1929 \\
Kiribati & 107.817 & 0,21 & Dólar de Australia & 1943 \\
Palau & 20.842 & 0,12 & Dólar de EEUU & 1944 \\
Micronesia & 107.862 & 0,28 & Dólar de EEUU & 1944 \\
Islas Marshall & 61.815 & 0,12 & Dólar de EEUU & 1944 \\
Timor del Este & 1.084 .971 & 0,37 & Dólar de EEUU & 2000 \\
Ecuador & 13.755 .680 & 60,48 & Dólar de EEUU & 2000 \\
El Salvador & 6.948 .073 & 33,2 & Dólar de EEUU & 2001 \\
Total & 25.523 .929 & 126,54 & & \\
*El PIB se mide con base en la tasa de cambio de paridad de poder de compra de Estados \\
Unidos.
\end{tabular}

Con la dolarización real, los precios y contratos de la economía, en especial los salarios, se establecen en dólares. Este tipo de dolarización responde a la dificultad para ajustar continuamente los precios y demás variables nominales, y al interés de los asalariados y las empresas en fijar sus precios en la moneda más estable en términos reales (Ize y Parrado, 2002). La dolarización real es poco común: aun en economías de alta dolarización financiera como Uruguay, Paraguay, Perú y Bolivia, los salarios y otros precios siguen denominados en moneda local.

${ }^{3}$ Aquí la dolarización es la adopción de una moneda extranjera en reemplazo de la local, así la primera no sea el dólar de Estados Unidos. En el caso del euro, la fecha de adopción es aquella en que se adoptó la moneda que precedió al euro. Datos del CIA World Factbook 2007. 
La dolarización financiera, en la que el dólar se usa para denominar depósitos, préstamos y otros contratos financieros, responde a la necesidad de una moneda que preserva el valor de los activos. Este tipo de dolarización, bastante común, obedece, entre otras razones, a que los agentes buscan disminuir la volatilidad del valor real de su portafolio de activos utilizando la moneda extranjera. En América Latina, Perú, Bolivia, Costa Rica, Uruguay y Paraguay muestran altos grados de dolarización financiera. La siguiente sección comenta en mayor detalle este tipo de dolarización.

\section{LA DOLARIZACIÓN FINANCIERA}

La dolarización financiera, también conocida como sustitución de activos y pasivos, consiste en usar el dólar para denominar depósitos, préstamos y otros contratos financieros, para preservar su valor.

Este tipo de dolarización, muy común en América Latina, se suele medir con el coeficiente de depósitos en moneda extranjera como proporción de los depósitos totales (Heysen, 2005).

\section{Gráfica 1}

Dolarización financiera en América Latina

Depósitos en moneda extranjera como porcentaje de depósitos totales (2004) Argentina: antes (2001) y después de la pesificación (2004)

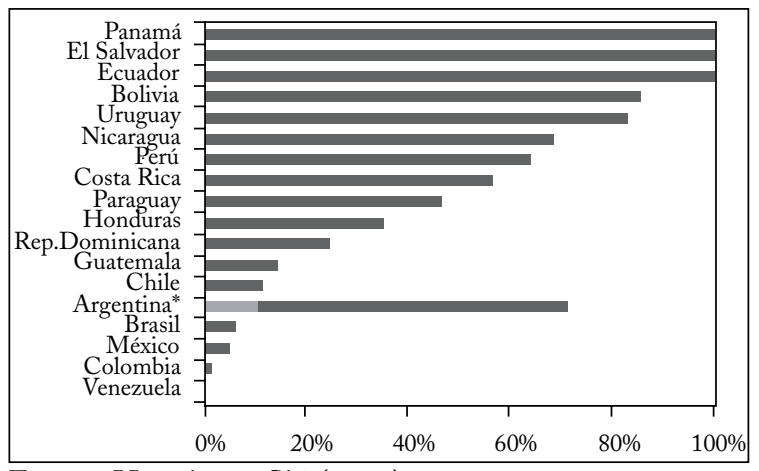

Fuente: Honohan y Shi (2001).

De acuerdo con la revisión teórica, tres factores determinan el mayor o menor grado de dolarización financiera de una economía: i) credibilidad de la autoridad monetaria y confianza en la moneda local, ii) volatilidad relativa de la moneda local y cobertura de riesgo, y iii) integración comercial y tamaño de la economía. 


\section{CREDIBILIDAD DE LA AUTORIDAD MONETARIA Y CONFIANZA EN LA MONEDA LOCAL}

Un factor común a todos los tipos de dolarización es la poca credibilidad de la autoridad monetaria y la desconfianza en la moneda local. Con una baja credibilidad en la autoridad monetaria y en la capacidad de la moneda local para cumplir la función de reserva de valor, los agentes prefieren resguardar su riqueza en otra moneda que les garantice su capacidad adquisitiva medida en moneda local.

Así, las diferencias en el grado de dolarización financiera entre países se explican en parte por diferencias en la calidad y la credibilidad de las instituciones, así como por restricciones administrativas y legales (De Nicoló et al., 2003).

A escala internacional, Honohan (2007), en un estudio de 76 países para el periodo 1990-2005, encontró que ningún país que haya mantenido una inflación inferior al 35\% anual tiene alta dolarización ${ }^{4}$, a excepción de los centros financieros. Y, además que ningún país que haya experimentado hiperinflación ha logrado escapar de un nivel alto de dolarización, excepto a través de su restricción legal.

En América Latina, el pasado de desórdenes macroeconómicos y episodios hiperinflacionarios de los ochenta y comienzos de los noventa justifica ${ }^{5}$, en algunos casos, la poca confianza en las políticas económicas y en la moneda local como reserva de valor.

Cuadro 3

Casos recientes de hiperinflación en América Latina

\begin{tabular}{ll}
\hline País & Años \\
\hline Argentina & 1989 y 1990 \\
Bolivia & 1984 y 1985 \\
Brasil & $1989,1990,1993$ y 1994 \\
Nicaragua & $1988,1989,1990$ y 1991 \\
Perú & 1989 y 1990 \\
\hline
\end{tabular}

Fuente: Rennhack R. y Nozaki M. (2006).

Para corroborar lo anterior, la gráfica 2 muestra la relación entre dolarización financiera e inflación en algunos países de América La-

${ }^{4}$ Para el autor, un país con alta dolarización tiene la mitad de los depósitos en moneda extranjera o está en el cuartil superior de una muestra de 130 países.

${ }_{5}^{5}$ La hiperinflación corresponde a los episodios en que la inflación llega al $1.000 \%$ anual (Dornbusch et al., 2004). 
tina entre 1980 y 1994, periodo en el que algunos de ellos tuvieron hiperinflación.

Cabe resaltar que los países que tuvieron eventos hiperinflacionarios $y$, por ende, una alta inflación promedio en ese periodo, exhiben una dolarización financiera mayor al 70\%, con excepción de Brasil, que mantiene un bajo nivel de dolarización mediante restricciones legales.

Por otra parte, países con economías de tamaño mediano y bajos niveles promedio de inflación (Chile, México, Colombia y Venezuela) muestran bajos niveles de dolarización financiera. Estos países han preservado la demanda de sus monedas mediante una combinación de políticas económicas sanas, instrumentos financieros indexados y restricciones legales (Rennhack y Nozaki, 2006).

\section{Gráfica 2}

Dolarización y poca credibilidad monetaria: evidencia empírica

Inflación (Promedio 1980-1994) vs. Dolarización de depósitos (2001)

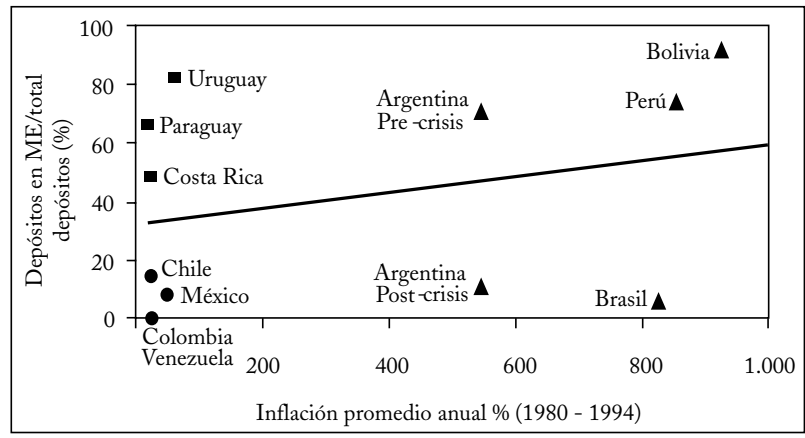

A Experimentaron hiperinflación

- No experimentaron hiperinflación

- Casos particulares

Fuente: IFS, FMI y Rennhack y Nozaki (2006).

Uruguay, Paraguay y Costa Rica, que no tuvieron una inflación promedio alta, tienen altos niveles de dolarización financiera que, como veremos, obedecen a su tamaño y grado de integración comercial y financiera con el exterior.

\section{VOLATILIDAD RELATIVA DE LA MONEDA LOCAL Y COBERTURA DE RIESGO}

Puesto que los contratos e instrumentos financieros se suelen ajustar periódicamente a los cambios en la inflación, este factor resalta que el nivel de inflación esperada no es el determinante de la dolarización 
financiera. Por el contrario, de acuerdo con este factor ${ }^{6}$, la dolarización financiera es el resultado de un ejercicio de portafolio de mínima varianza que refleja la relación entre volatilidad de la inflación, volatilidad del tipo de cambio real, y la correlación entre ambas. Según esto, existirá una fuerte disposición de los agentes a dolarizar sus activos si el riesgo de inflación no esperada es alto.

Así, los agentes, que se suponen adversos al riesgo, escogerán la combinación de instrumentos financieros en pesos y dólares que les permita minimizar el riesgo de su portafolio de riqueza real.

Para probar esta hipótesis, siguiendo a Ize y Levy (1998) y con datos de inflación y tasa de cambio nominal ${ }^{7}$, se construyó una serie histórica mensual de inflación y de devaluación real. Con estas series se estimó para varios países de América Latina la dolarización financiera estimada por cobertura, o grado de dolarización correspondiente a la combinación de activos en pesos y dólares que arroja la mínima volatilidad de la capacidad adquisitiva de los agentes.

Esta estimación se realizó para dos periodos de diez años, 19811990 y 1995-2004, los cuales difieren en los resultados de la inflación: el primero se caracterizó por episodios hiperinflacionarios en algunos países, mientras que el segundo se destacó por los logros en la lucha contra la inflación.

Gráfica 3

Dolarización como cobertura: periodos de inestabilidad (1981-1990) y estabilidad (1995-2004) de precios de las economías latinoamericanas

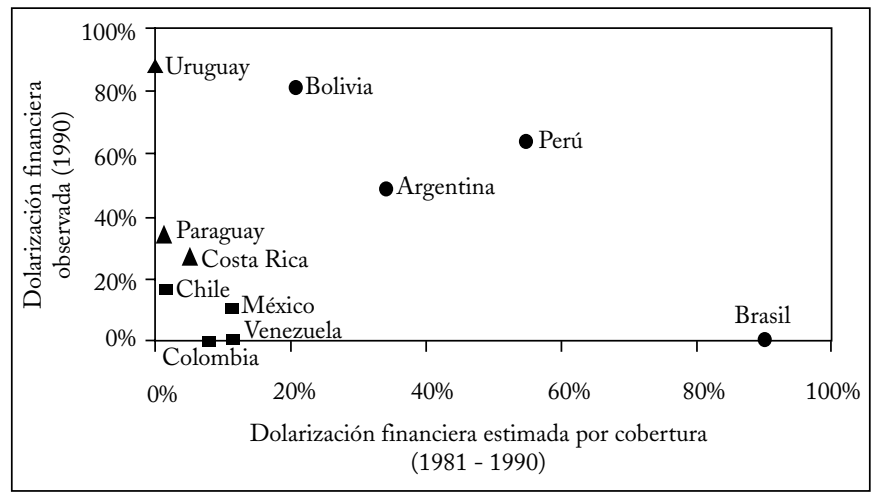

${ }^{6}$ En este factor coinciden, entre otros, Ize y Levy (2003), Rennhack y Nozaki (2006), Ize (2006), De Nicoló et al. (2003), Ize y Levy (1998) y BID (2004).

${ }^{7}$ Información del IFS, FMI. 


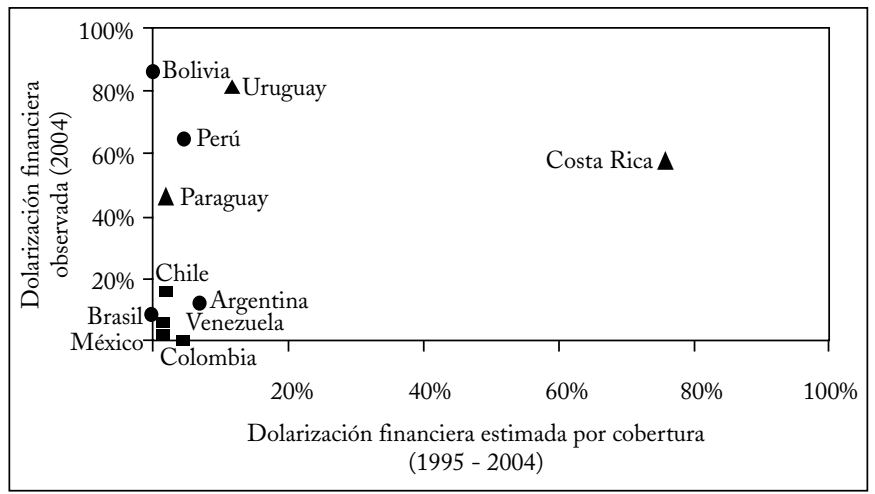

Experimentaron hiperinflación

- No experimentaron hiperinflación

- Economías pequeñas e integradas

Fuente: IFS, FMI y Singh et al. (2005), con base en Rennhack y Nozaki (2006) e Ize y Levy (2003).

En el periodo 1981-1990 (izquierda), las economías con alta volatilidad de la inflación frente a la volatilidad de la tasa de cambio real (Bolivia, Perú, Argentina) y correlaciones lejanas de la unidad, tuvieron altos niveles de dolarización, como supone el índice de dolarización financiera estimada por cobertura. La excepción es Brasil, que, como ya se mencionó, ha evitado la dolarización a través de normas legales.

En cambio, economías con baja volatilidad de la inflación frente a la volatilidad de la tasa de cambio real (Colombia, Chile, México, Venezuela) o que disponen de instrumentos indexados ${ }^{8}$, y que no son economías pequeñas e integradas, tienen un bajo nivel de dolarización, acorde con el índice mencionado.

En el periodo 1995-2004 (derecha), América Latina se distanció del pasado hiperinflacionario y del desorden macroeconómico. Prueba de ello es que la dolarización financiera estimada por cobertura disminuyó notoriamente en casi todos los países.

Los países sin pasado hiperinflacionario que siguieron esa tradición (Chile, Colombia, México y Venezuela) se mantuvieron cerca del origen, confirmando que su dolarización financiera es acorde con un bajo nivel de dolarización financiera estimada por cobertura.

Sin embargo, el nivel de dolarización observada no disminuyó en igual medida en todos los países con pasado hiperinflacionario, hecho

${ }^{8}$ Chile con la unidad de fomento (UF) y Colombia con la UVR (antes UPAC). El caso de Chile, que se describe en el anexo, es aleccionador a este respecto. 
que es evidente en Perú y Bolivia, que aún mantienen altos niveles de dolarización. Lo anterior muestra la fuerte persistencia de la dolarización en algunos países con pasados hiperinflacionarios ${ }^{9}$. Cabe resaltar que Argentina, como consecuencia de la caída de la caja de conversión en $2001^{10}$, decidió “pesificar" la economía en 2002, razón por la cual pasó de un nivel de dolarización de los depósitos del 71,5\% en 2001 al 4,2\% en 2002.

Por otra parte, subsisten altos niveles de dolarización financiera en Costa Rica, Uruguay y Paraguay, que son países pequeños e integrados. A continuación se aborda este factor.

\section{TAMAÑO DE LA ECONOMÍA E INTEGRACIÓN COMERCIAL Y FINANCIERA}

Como ya se afirmó, la dolarización total se justifica en economías muy integradas con Estados Unidos y que, por ende, experimentan ciclos similares, así como en economías pequeñas en las que los precios ya están denominados en dólares y la mayor parte de los productos se comercia con el exterior (Sachs y Larrain, 1999). En este tipo de economías pequeñas cuyo nivel de integración con el exterior implica que el manejo de una moneda extranjera es más conveniente, la dolarización financiera refleja la estructura comercial de la economía (Ize y Parrado, 2002).

También existen evidencias que indican un vínculo importante entre la dolarización real y financiera, donde la primera, debido al desarrollo del sector real frente a la globalización y la liberalización del comercio, presiona a la segunda. En tales casos, puede ser nocivo tratar de evitar la dolarización financiera (Ize y Levy, 1998).

Para corroborar este factor se comparó el grado de integración comercial de la economía, medido como el coeficiente de exportaciones más importaciones de bienes y servicios como proporción del PIB, con la dolarización de depósitos.

\footnotetext{
${ }^{9}$ Esta persistencia se conoce en la literatura como histéresis o ratchet effect, por la cual los agentes, una vez sustituyen la moneda local por el dólar, tienden a abandonarla muy lentamente, aunque la razón para haber reemplazado la moneda local ya no esté presente. Las causas de este efecto son la memoria de los agentes y el costo inicial que se pagó por pasarse al dólar (Honohan y Shi, 2001).

${ }^{10} \mathrm{La}$ caja de conversión es un arreglo cambiario en virtud del cual el banco central solo puede emitir moneda local si la emisión es respaldada con reservas internacionales a una tasa de cambio determinada. Hong Kong es una de las economías que hoy utiliza este arreglo cambiario, mientras que Argentina lo mantuvo desde comienzos de los noventa hasta 2001.
} 
Gráfica 4

Dolarización en países pequeños y muy integrados: evidencia empírica Integración (Intercambio comercial/PIB 1997-2004 vs. Dolarización de depósitos 2004)

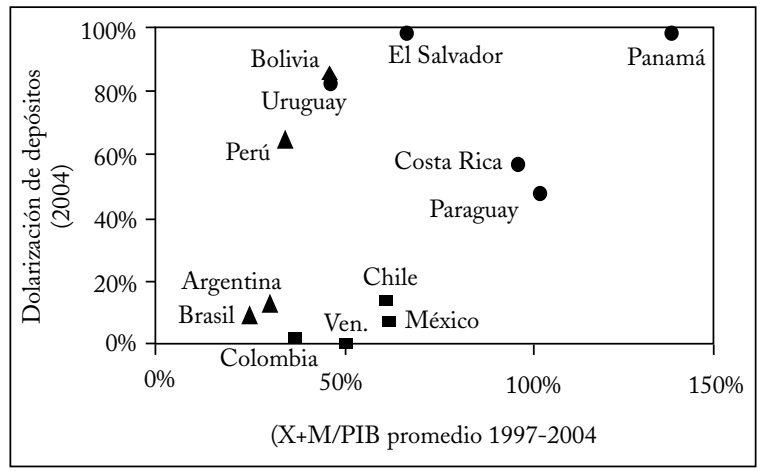

Experimentaron hiperinflación

- No experimentaron hiperinflación

- Economías pequeñas e integradas

Fuente: IFS y FMI. Por intercambio comercial se entiende la suma de exportaciones e importaciones de bienes, más la suma de créditos y débitos por pago de servicios.

Según la gráfica 4, las economías de tamaño pequeño muy integradas con el exterior presentan altos grados de dolarización de los depósitos (Costa Rica, Panamá, El Salvador, Uruguay y Paraguay), mientras que los países con niveles intermedios de integración comercial, y que no han sufrido periodos de hiperinflación, exhiben bajos niveles de dolarización financiera (Colombia, Chile, Venezuela y México).

Esto indica que la decisión de dolarizar en economías pequeñas y muy integradas responde a la conveniencia de aprovechar el grado de sincronía con la economía que emite la moneda.

Además, algunas de estas economías pequeñas e integradas ofrecen ventajas a los depósitos de los no residentes, lo que también presiona la dolarización financiera. Los casos más sobresalientes son Hong Kong, Costa Rica, Djibouti, Líbano, Islas Maldivas y Uruguay (Honohan, 2007).

\section{PRINCIPALES EFECTOS DE LA DOLARIZACIÓN FINANCIERA}

La siguiente sección revisa las principales consideraciones y consecuencias asociadas a la dolarización financiera teniendo en cuenta la teoría y la evidencia empírica disponible. 


\section{EL DÓLAR COMO ALTERNATIVA DE RESERVA DE VALOR}

Permitir que los agentes utilicen el dólar como reserva de valor les brinda una alternativa para resguardar el valor real de su riqueza, por ejemplo, frente a la inflación o a la depreciación de la moneda local. Así mismo, los agentes contarán con un activo adicional para conformar su portafolio de activos, que les reporta beneficios por la diversificación de riesgo.

No obstante, la experiencia internacional reciente demuestra que la utilización de la moneda extranjera como reserva de valor no sólo obedece a la confianza en la moneda local y a la aversión al riesgo de los agentes. Puesto que ofrecen una remuneración inferior a los depósitos en moneda local, el público no siempre está dispuesto a utilizar los depósitos en moneda extranjera, especialmente si existen expectativas de apreciación de la moneda local o de inflación baja y controlada, o una tasa de interés en moneda local muy atractiva.

Por el contrario, si existen perspectivas de depreciación de la moneda local o de desorden monetario, el público deseará utilizar la moneda extranjera como reserva de valor; en este caso, los agentes están dispuestos a recibir una menor remuneración porque estiman que la protección contra el riesgo cambiario es valiosa.

\section{Profundización DEL SISTEMA FINANCIERO}

En economías inflacionarias y no dolarizadas, donde la moneda local no cumple la función de reserva de valor, el público busca resguardar el valor de sus activos por fuera del sistema financiero, bien sea en el exterior o en moneda extranjera en efectivo.

Por ello, la dolarización financiera devuelve la función de reserva de valor a los contratos financieros y permite tener un sistema financiero más profundo, pero sólo en economías inflacionarias (De Nicoló et al., 2003).

\section{COSTOS DE TRANSACCIÓN Y DISPONIBILIDAD DE COBERTURA NATURAL}

En economías pequeñas y muy abiertas al comercio existe una alta propensión a la dolarización financiera, la cual puede ser un resultado natural y saludable del desarrollo del sector real frente a la globalización y la liberalización del comercio (Ize y Levy, 2005). 


\section{IMPACTO SOBRE EL NIVEL DE RIESGO SISTÉMICO}

Si se permitiera que los agentes tengan depósitos en moneda extranjera, los intermediarios financieros asumirían inmediatamente un riesgo cambiario, el cual pueden mantener dentro de su balance o transferirlo. Si deciden mantener el riesgo cambiario o no pueden transferirlo, la exposición a este riesgo genera un efecto balance potencial, que aumenta la vulnerabilidad de los sistemas financieros al riesgo de solvencia y de liquidez ante una depreciación considerable ${ }^{11}$.

Por otra parte, si los intermediarios financieros que reciben depósitos en dólares logran transferir el riesgo cambiario otorgando créditos en moneda extranjera, esta cobertura cambiaria implica que están intercambiando el riesgo cambiario por riesgo de crédito.

El prestatario de un crédito en moneda extranjera asume el riesgo cambiario, por lo que el efecto balance simplemente se traslada del sector financiero al real. De modo que si los ingresos del deudor no están denominados o indexados en moneda extranjera y ocurre una depreciación considerable, la liquidez y solvencia del deudor disminuye y quizá no pueda cumplir sus compromisos con el intermediario financiero, lo que incrementa la cartera vencida y el riesgo sistémi$\mathrm{co}^{12}$, y se convierte a su vez en un determinante de crisis bancarias y cambiarias.

El efecto balance ha sido reconocido como un determinante de los últimos episodios de crisis:

- Eichengreen (2001) documenta que la existencia de una exposición cambiaria considerable, consistente en obligaciones en moneda extranjera dentro y fuera de balance, fue un factor relevante en las crisis de Turquía y Argentina de comienzos del siglo XXI.

- Calvo, Izquierdo y Mejía (2004) documentan que la dolarización de pasivos en las economías emergentes es uno de los más importantes determinantes de la probabilidad de ocurrencia de una detención súbita ${ }^{13}$.

- Ize y Levy (2005) concluyen que la dolarización ha complicado la respuesta de política económica en varios episodios de crisis o previos a la crisis y, en algunos

${ }^{11}$ Cayazzo et al. (2006). El efecto balance y su impacto en los riesgos de solvencia y de liquidez y en la estabilidad macroeconómica son reconocidos ampliamente en la literatura.

${ }^{12}$ Leiderman et al. (2006) encuentran que en Perú, con alta dolarización financiera, el tipo de cambio real causa la cartera vencida, a diferencia de Chile, una economía poco dolarizada.

${ }^{13} \mathrm{O}$ fuerte reducción de los flujos de capital, que suelen desencadenar fuertes depreciaciones y desórdenes financieros, y resultan en bajas tasas de inversión y crecimiento (Calvo, Izquierdo y Mejía, 2004). 
casos, ha sido identificada como la fuente de vulnerabilidad financiera que disparó la crisis. También concluyen que la dolarización financiera genera mayor volatilidad del producto de un país.

Sin embargo, los efectos nocivos del traslado del riesgo cambiario del sector financiero al sector real pueden ser absorbidos adecuadamente si las firmas del sector real que asumen el riesgo cambiario denominan o indexan sus ingresos en moneda extranjera, como es el caso de las firmas exportadoras. De existir este tipo de cobertura natural en el balance del sector real de la economía, el traslado puede ser adecuado.

Para América Latina existe evidencia que demuestra que el traslado del riesgo cambiario del sector financiero al real en economías con alto grado de dolarización financiera se ha realizado al sector no transable de la economía (Rennhack y Nozaki, 2006, y BID, 2004).

E1 traslado de riesgo cambiario al sector real tiene un incentivo adicional. Puesto que las tasas de interés de los préstamos en dólares suelen ser inferiores a las tasas de los préstamos en moneda local, los agentes tienden a subestimar el costo del endeudamiento (Singh et al., 2005). Los deudores en dólares simplemente aprovechan una tasa nominal inferior, desconociendo la probabilidad de un fuerte aumento de la tasa de cambio y el efecto balance que puede resultar.

\section{Gráfica 5}

Traslado del riesgo cambiario al sector real Obligaciones en moneda extranjera como proporción de obligaciones totales, para empresas no exportadoras (2001)

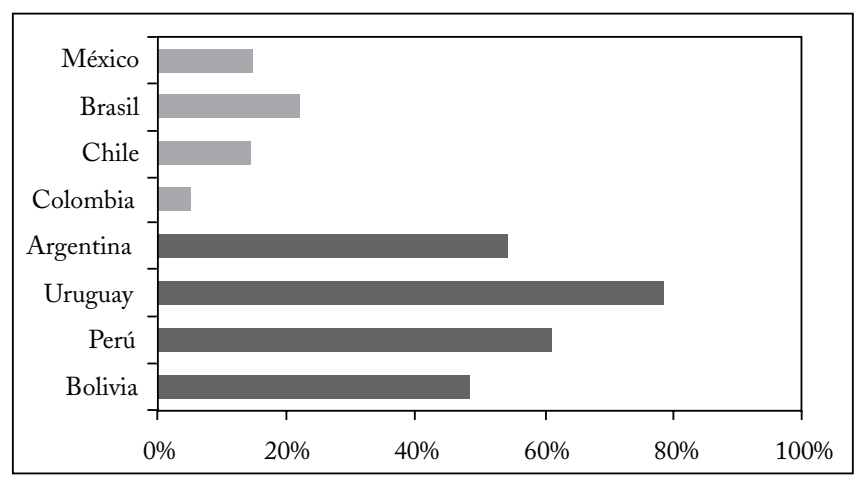

Fuente: Rennhack y Nozaki (2006). 
Gráfica 6

Traslado del riesgo cambiario al sector real

Cartera hipotecaria y de consumo en dólares

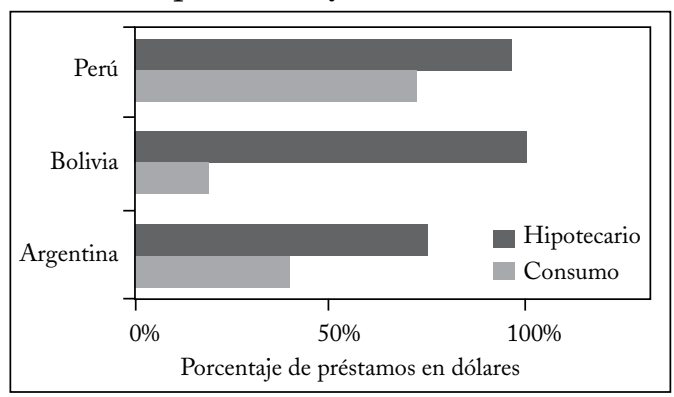

Fuente: BID (2004). Los datos de Perú corresponden a 1996-2002, los de Argentina a 19962001 y los de Bolivia a 2002.

\section{LA FUNCIÓN DE PRESTAMISTA DE ÚLTIMA INSTANCIA}

La ausencia de un prestamista de última instancia para los depósitos en moneda extranjera puede llevar a que las corridas bancarias sean más frecuentes y, una vez iniciadas, más difíciles de detener (Gulde et al., 2003); debido a la dificultad para mantener activos líquidos en moneda extranjera y a la limitada capacidad del prestamista de última instancia para proveer liquidez en moneda extranjera.

Gulde et al. (2003) encuentran evidencias que señalan a la dolarización, especialmente a la dolarización financiera, como un factor que complica los episodios de corridas bancarias y que puede determinar su ocurrencia y desarrollo (cuadro 4).

Cuadro 4

Casos de corridas bancarias

Porcentaje

\begin{tabular}{lccccccc}
\hline & $\begin{array}{c}\text { Turquía } \\
(1994)\end{array}$ & $\begin{array}{c}\text { Argentina } \\
(1995)\end{array}$ & $\begin{array}{c}\text { Bulgaria } \\
(1996)\end{array}$ & $\begin{array}{c}\text { Rusia } \\
(1998)\end{array}$ & $\begin{array}{c}\text { Ecuador } \\
(1999)\end{array}$ & $\begin{array}{c}\text { Argentina } \\
(2001)\end{array}$ & $\begin{array}{c}\text { Uruguay } \\
(2002)\end{array}$ \\
\cline { 2 - 8 } Dolarización de depósitos & 46 & 50 & 40 & $18^{14}$ & 76 & 70 & 85 \\
\hline
\end{tabular}

Fuente: Gulde et al. (2003).

Para facilitar el cumplimiento de la función de prestamista de última instancia podría ser necesario utilizar las reservas internacionales o

\footnotetext{
${ }^{14}$ Los intermediarios financieros presentaban además una gran exposición cambiaria fuera de balance (ibíd.)
} 
crear un fondo de liquidez. En cualquier caso, tener una mayor parte de la liquidez del banco central en moneda extranjera significa en general una rentabilidad menor $y$, por tanto, un costo de agencia que lleva a mantener tenencias subóptimas de liquidez en dólares y a otorgar un subsidio implícito a la intermediación en dólares, con cargo a los contribuyentes (Ize, Kiguel y Levy, 2006).

Si en vez de hacerlo él mismo, el banco central o el supervisor forzara a los intermediarios a mantener requisitos de liquidez en moneda extranjera más elevados, este costo se trasladaría a los depositantes mediante una menor remuneración o al prestatario a través de una mayor tasa de interés.

\section{LA FUNCIÓN DE SUPERVISIÓN DEL SECTOR FINANCIERO}

Si existe un descalce en el balance de los bancos, un movimiento de la tasa de cambio puede afectar rápidamente la solidez del sistema bancario, dejando poco tiempo para detectarlo y para que actúen las autoridades (Gulde et al., 2003). Por ello, la supervisión está obligada a tener más y mejores herramientas para prevenir y afrontar los problemas del sector financiero. Se debe asegurar que los bancos tengan el respaldo suficiente para cubrir sus riesgos ante choques excepcionales, y lograr que interioricen y capitalicen los riesgos que asumen.

\section{LA POLÍTICA CAMBIARIA Y MONETARIA}

E1 efecto balance mencionado en una sección anterior genera el efecto del temor a la flotación. Este efecto se refiere a que los agentes, en especial el banco central, son fuertemente adversos a la volatilidad de la tasa de cambio e incluso inducen a fijar metas cambiarias.

La consecuencia directa de la aversión a los movimientos de la tasa de cambio es la restricción de la habilidad de la autoridad monetaria y cambiaria para adoptar políticas autónomas anticíclicas ${ }^{15}$.

La evidencia muestra que los países con alta dolarización de pasivos tienden a tener un tipo de cambio menos flexible ${ }^{16}$, para lo

\footnotetext{
${ }^{15}$ Honig (2005), Leiderman et al. (2006), Ganapolsky (2003), De Nicoló et al. (2003).

${ }^{16}$ Según Honig (2005), un incremento del 1\% en la razón depósitos en moneda extranjera/pasivos totales de los bancos incrementa la probabilidad
} 
cual deben asumir el costo -fiscal- de tener que intervenir con más frecuencia en el mercado monetario y cambiario (Ganapolsky, 2003, y Berkmen y Cavallo, 2007), y de enfrentar dificultades en la fijación de metas de inflación ${ }^{17}$.

Rennhack y Nozaki (2006) elaboraron un índice de temor a la flotación, con el cual determinaron un indicador de flexibilidad cambiaria de facto ${ }^{18}$, que oscila entre cero (tipo de cambio fijo) e infinito (total flexibilidad).

Utilizando este indicador de flexibilidad cambiaria, la gráfica 7 muestra que los países con mayor dolarización financiera tienden a tener un tipo de cambio menos flexible.

\section{Gráfica 7}

Países con alta dolarización de pasivos tienden un tipo de cambio menos flexible. Dolarización financiera (2004) y flexibilidad de facto (1990-2004)

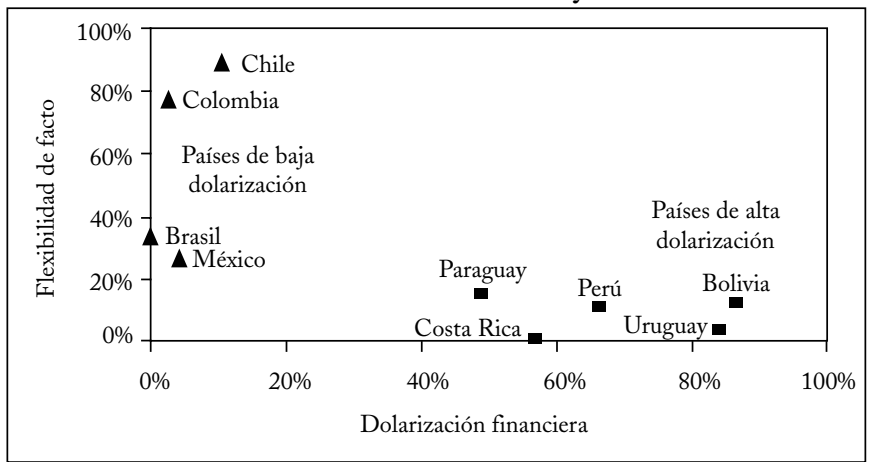

Fuente: Rennhack y Nozaki (2006).

La evidencia empírica corrobora entonces que los países latinoamericanos con mayor dolarización financiera tienen un tipo de cambio menos flexible. Por ello, en estos países son válidas las ventajas y desventajas de los regímenes de tasa de cambio fija (cuadro 5).

de que el país elija un tipo de cambio fijo en un $0,3 \%$.

${ }^{17}$ Leiderman et al. (2006) encuentran evidencia de que la fijación de metas de inflación es más difícil en una economía con alta dolarización financiera.

${ }^{18}$ Este indicador, desarrollado por Calvo y Reinhart (2002), y citado por Rennhack y Nozaki (2006), mide la variabilidad de la tasa de depreciación de la tasa de cambio nominal en relación con la suma de la variabilidad de las reservas internacionales netas y de las tasas de interés de corto plazo. 
Cuadro 5

Principales ventajas y desventajas del tipo de cambio fijo

\begin{tabular}{ll}
\hline \multicolumn{1}{c}{ Ventajas } & \multicolumn{1}{c}{ Desventajas } \\
\hline - Induce una mayor disciplina monetaria y & - Reduce la autonomía de la política \\
reduce la desconfianza en la moneda & monetaria y la capacidad de adoptar políticas \\
- Reduce la volatilidad cambiaria y genera & anticíclicas \\
confianza & - Evidencia de menor crecimiento de la \\
- Evidencia de mayores niveles de inversión & productividad \\
extranjera & - Dificulta realizar ajustes nominales ante \\
- Mejores resultados en la lucha contra la & desequilibrios externos \\
inflación & - Puede generar apreciación real y desajustes \\
- Reducción de los costos de transacción & cambiarios que terminan en ataques \\
& especulativos y crisis cambiaria \\
\hline
\end{tabular}

Fuente: Gosh et al. (1996) y Sachs y Larrain (1999).

La última desventaja -que los tipos de cambio fijos son más propensos a ataques especulativos y crisis cambiarias- se magnifica con la posibilidad de hacer depósitos en moneda extranjera. Debido a que la expectativa de crisis bancaria o cambiaria puede generar una “corrida del peso", que se materializará al trasladarse los depósitos a dólares, disminuyendo así la demanda de moneda local y reforzando la expectativa de la crisis.

Por otra parte, los deudores en dólares (bancos y sector real), confiados en la existencia del efecto balance y en el temor a la flotación de la autoridad monetaria, tienen incentivos para asumir un riesgo cambiario excesivo. Así, ante una garantía implícita de estabilidad cambiaria, los agentes aprovechan que las tasas de los créditos en dólares suelen ser inferiores a las tasas en moneda local, sin internalizar apropiadamente el riesgo cambiario (riesgo moral).

Por último, el efecto balance también puede distorsionar los mecanismos de transmisión monetaria. Por ejemplo, si el banco central pretende adoptar una política monetaria contraccionista y el promedio de los agentes del sector real es deudor en dólares, un aumento de la tasa de interés induce una apreciación de la tasa de cambio que aumenta la riqueza y el consumo (Gómez, 2007). Además, el efecto balance puede llevar a que la depreciación, por lo general expansiva, tenga efectos contraccionistas.

\section{REPUTACIÓN Y CREDIBILIDAD DEL BANCO CENTRAL}

La dolarización de depósitos es un mecanismo mediante el cual los consumidores y las empresas enfrentan la incertidumbre de la variación de precios y la falta de confianza en la economía. Por tanto, 
el hecho de permitir la dolarización financiera tiene impacto en la reputación y la credibilidad del banco central y de su moneda.

En los países en desarrollo, cuyas instituciones y cuya economía no tienen un alto grado de confiabilidad y reputación que haga posible que su moneda sea libremente convertible a nivel internacional, el permitir la dolarización de pasivos puede llevar a pensar que el banco central espera un aumento en la incertidumbre de la variación de precios, o que espera perder el control monetario de la economía ${ }^{19}$.

Por el contrario, en países con alta confiabilidad y reputación de sus instituciones y de su economía, que emiten monedas de libre convertibilidad, el hecho de permitir la dolarización financiera se puede interpretar como una señal de confianza en la moneda local.

\section{IMPACTO EN EL FINANCIAMIENTO LOCAL}

Como ya se mencionó, los intermediarios financieros que reciben depósitos en moneda extranjera tratarán de cubrir sus posiciones extendiendo créditos en la misma moneda, trasladando el riesgo cambiario al sector real.

Además, puesto que puede existir un límite a la absorción de créditos en moneda extranjera dentro del sector real, los intermediarios pueden optar por hacer depósitos en el exterior.

De acuerdo con la evidencia que presentan Honohan y Shi $(2001)^{20}$, al menos la mitad de los depósitos en moneda extranjera que reciben los intermediarios financieros se colocan fuera del país, lo cual lleva a una disminución de la oferta de crédito en la economía y a un aumento de la tasa de interés real.

\section{Persistencia de la dolarización}

Se ha documentado que la dolarización suele emerger progresivamente en respuesta a la inestabilidad macroeconómica, mostrando un patrón bien definido: primero se reemplaza la moneda local como reserva de valor, manteniendo dólares en efectivo. Luego se empieza

\footnotetext{
${ }^{19}$ Esta inconvertibilidad lleva a la incapacidad para endeudarse en moneda nacional a largo plazo en el mercado doméstico o en el exterior (deuda soberana y privada), en lo que se conoce como "pecado original". Esto es consecuencia de la falta de políticas fiscales y monetarias creíbles, así como del subdesarrollo financiero, entre otros factores (Bordo et al., 2003).

${ }^{20}$ Honohan y Shi encontraron este resultado en un análisis de regresión para una muestra de 58 economías emergentes.
} 
a utilizar la moneda extranjera para algunas transacciones, lo cual presiona la dolarización real. Y, después, para evitar una posible desintermediación financiera, se permite que los bancos reciban depósitos en dólares ${ }^{21}$.

Pero, aun en ausencia de inestabilidad económica pasada o presente que estimule la dolarización, permitir que los agentes tengan depósitos en dólares puede llevar a que ésta se propague fácilmente cuando existe una expectativa de crisis bancaria o cambiaria que genere una "corrida del peso", la cual no solo reforzará la expectativa de crisis, sino que finalmente propagará la dolarización.

También se ha documentado que la dolarización subsiste después de que han desaparecido las causas que la generaron, por lo que la des-dolarización es un proceso lento, poco frecuente y difícil. Las explicaciones más comunes de este hecho son la histéresis causada por el recuerdo de traumas del pasado (inflación, devaluación, crisis bancaria, etc.), el costo inicial que se pagó por pasarse al dólar y el incentivo para mantener el dólar como reserva de valor cuando existe temor a la flotación ${ }^{22}$.

\section{CONSIDERACIONES PARA EL CASO COLOMBIANO}

Teniendo en cuenta que hoy los agentes ya tienen la posibilidad de adquirir y mantener activos y pasivos en moneda extranjera ${ }^{23}$, en esta sección se presentan algunas consideraciones sobre la dolarización financiera en el caso colombiano.

\section{EN COLOMBIA NO EXISTE NINGUNA DE LAS CAUSAS DE DOLARIZACIÓN TOTAL O FINANCIERA Y, POR TANTO, SUS VENTAJAS SON MUY LIMITADAS}

La economía colombiana se caracteriza por: i) una alta credibilidad en la política monetaria y en el banco central; ii) un tamaño mediano, con un nivel de integración medio que, medido por la suma de exportaciones e importaciones como proporción del PIB, es inferior al $29,5 \%$ en promedio, y cuyas exportaciones como porcentaje del

${ }^{21}$ Castillo y Winkelried (2007), citando a Savastano (1996).

${ }^{22}$ Honohan y Shi (2001), Singh et al. (2005) y Castillo y Winkelried (2007).

${ }^{23}$ Los agentes pueden adquirir dólares en efectivo, mantener instrumentos indexados en dólares (fondos de pensiones voluntarias en moneda extranjera) y tener cuentas de compensación y de depósito en el exterior. 
PIB son inferiores al 13,9\%, entre 1994 y $2005^{24}$, y iii) un historial de inflación y devaluación moderada y poco traumática.

Es decir, las causas que justifican la dolarización financiera, real, de medios de pago o total, no existen en el país.

\section{HOY NO PARECE HABER INCENTIVOS PARA QUE LOS RESIDENTES TENGAN DEPÓSITOS EN DÓLARES}

De acuerdo con las características y el entorno de la economía colombiana en la actualidad, la dolarización financiera no incentivaría a realizar depósitos en moneda extranjera, debido a que el dólar no parece cumplir en el futuro inmediato todas o algunas de las funciones clásicas de la moneda: i) el dólar no es un medio de pago dentro de la economía colombiana y el peso cumple esta función de manera eficiente; ii) el dólar no se utiliza para indexar los precios, de modo que tampoco es unidad de cuenta, y iii) el dólar no parece un buen sustituto de reserva de valor para el peso.

Con respecto a esta última función, hoy las condiciones económicas desincentivan al público a considerarlo como un sustituto de reserva de valor porque: i) el peso cuenta con la confianza de los agentes, respaldada por la credibilidad de la autoridad y la política monetaria; ii) para el público en general, que en promedio tiene ingresos bajos y medio-bajos en pesos y egresos en pesos, no existe incentivo para adoptar una estrategia de diversificación, y iii) para la parte del público de ingresos altos y medio-altos, que tiene un incentivo para adoptar una estrategia de diversificación, ya existen mecanismos que se lo permiten: activos denominados o indexados en moneda extranjera y la posibilidad de abrir cuentas en el exterior.

Además, las condiciones financieras que hoy tendría un depósito en dólares en Colombia no incentivan a utilizarlo porque: i) la tasa de interés de los depósitos en dólares es en general inferior a la de los depósitos en moneda local. Esta baja rentabilidad frente a los depósitos en pesos hace pensar que no existe incentivo financiero para que el público traslade sus depósitos a dólares, y ii) la existencia de expectativas de apreciación o baja depreciación del peso, igual que la

\footnotetext{
${ }^{24}$ Datos del IFS, FMI. Según el DANE, en 2006 las exportaciones de bienes y servicios como porcentaje del PIB ascendieron al $19 \%$, mientras que la suma de exportaciones e importaciones de bienes y servicios ascendió al 41\% (sin incluir transferencias corrientes ni renta de los factores).
}

Revista de Economía Institucional, vol. io, N. ${ }^{\circ}$ i8, Primer semestre/20o8, PP. 3r3-34I 
baja remuneración de los depósitos en dólares, resulta en la inexistencia de un incentivo financiero para que el público desee trasladar sus depósitos a dólares.

Sin embargo, las condiciones financieras antes mencionadas pueden revertirse rápidamente si el público tiene expectativas de desorden cambiario o monetario.

\section{LA DOLARIZACIÓN FINANCIERA PARECE IR EN CONTRAVÍA DE ALGUNOS OBJETIVOS Y POLÍTICAS DEL BANCO DE LA REPÚBLICA}

Cuando desmontó la banda cambiaria en 1999, el Banco de la República privilegió la autonomía monetaria y la movilidad de capitales frente a un compromiso de tasa de cambio.

Si se permitiera la dolarización financiera, debido al efecto balance y al temor a la flotación, el Banco de la República tendría presiones para mantener un nivel y una volatilidad de la tasa de cambio que garanticen la estabilidad y la solvencia de los sectores financiero y real, así como la riqueza de los ahorradores y los deudores.

Y debido a la necesidad de intervenir más activamente en el mercado cambiario para evitar cambios bruscos en el nivel y la volatilidad de la tasa de cambio, el Banco de la República podría verse abocado a asumir el costo de dicha intervención, así como las dificultades que impone al cumplimiento de las metas de inflación.

\section{LA DOLARIZACIÓN FINANCIERA RESTRINGE LA CAPACIDAD DEL BANCO DE LA REPÚBLICA PARA ADOPTAR POLÍTICAS MONETARIAS ANTICÍCLICAS}

Como vimos, el efecto balance distorsiona los mecanismos de transmisión monetaria. Por ejemplo, si el promedio de los agentes del sector real es deudor en dólares, una decisión del Banco de la República de adoptar una política monetaria expansionista podría verse enfrentada al efecto recesivo de la depreciación del peso y del efecto balance.

Y si juzgara conveniente adoptar una política monetaria contraccionista, y el promedio de los agentes del sector real fuera deudor en dólares, un aumento de la tasa de interés apreciaría la tasa de cambio y aumentaría la riqueza y el consumo. 


\section{LA EXPERIENCIA INTERNACIONAL DEMUESTRA QUE LA DOLARIZACIÓN DE DEPÓSITOS HACE MÁS VULNERABLE A LA ECONOMÍA ${ }^{25}$}

Como se documentó anteriormente, la dolarización financiera incrementa el riesgo sistémico y hace más vulnerable la economía a choques externos. Las consecuencias específicas de la dolarización financiera que hacen más vulnerable a la economía son las siguientes: i) genera un efecto balance en el sector financiero y real por exposición cambiaria, por lo que suscita en el banco central un temor a la flotación y presiones para mantener la estabilidad de la tasa de cambio, en contra de la autonomía monetaria; ii) aumenta la probabilidad de que un choque adverso lleve a una detención súbita y a una crisis gemela, y iii) debido al efecto balance, distorsiona los mecanismos de transmisión monetaria, con lo cual, por ejemplo, la expansión monetaria y la depreciación resultante puede llegar a ser una fuente de contracción.

Además, el efecto balance potencial que se puede generar por el traslado del riesgo cambiario al sector real es alto. En Colombia, con un coeficiente de exportaciones como proporción del PIB $^{26}$ cercano al 19\%, el riesgo de dicho traslado es considerable.

ES CONTRADICTORIO PERMITIR QUE EL PÚBLICO TENGA DEPÓSITOS EN MONEDA EXTRANJERA AL TIEMPO QUE SE IMPONEN CONTROLES A LA MOVILIDAD DEL CAPITAL

Los controles a la entrada de capitales y al endeudamiento externo tienen el objetivo de hacer más lento y difícil el intercambio de dólares y pesos (dólares por pesos en un entorno de apreciación como el actual, y pesos por dólares en un entorno de depreciación).

Además de que no es claro que existan incentivos para que el público haga depósitos en dólares en la actualidad, el hecho de permitir depósitos en moneda extranjera abre la posibilidad de que el público lleve a cabo una "corrida de pesos" a dólares en una situación de expectativas de depreciación, reforzando esa expectativa al disminuir la demanda de pesos, es decir, los depósitos en dólares se pueden convertir en un factor desestabilizador y procíclico.

\footnotetext{
${ }^{25}$ Calvo, Izquierdo y Mejía (2004) y BID (2004).

${ }^{26}$ Indicador que es útil para estimar la capacidad de absorción del traslado del riesgo cambiario del sector financiero al real.
} 
Y si se permitiera el endeudamiento local en moneda extranjera sería necesario que el efecto costo de los controles a la entrada de capitales y al endeudamiento externo se extendiera a los préstamos en dólares que otorgarían los bancos locales.

\section{LA DOLARIZACIÓN REQUIERE PREVIAMENTE GRANDES CAMBIOS Y MEJORAS}

\section{En la supervisión bancaria}

La supervisón prudencial debe asegurar que las instituciones financieras sean conscientes de los descalces en moneda extranjera dentro de su balance y de la exposición cambiaria de su cartera, y que los riesgos asociados se evalúen correctamente.

Así mismo, la función del supervisor se vuelve esencial porque debe asegurar que los bancos tengan respaldo suficiente para cubrir sus riesgos ante choques excepcionales.

Además, la supervisión se debe fortalecer previamente para vigilar y controlar el lavado de activos.

\section{En la supervisión del sector real}

La supervisión del sector real también debe lograr que los agentes interioricen los riesgos de mantener depósitos y obligaciones en moneda extranjera, prestando especial atención a las vulnerabilidades que surgen de un ambiente dolarizado.

\section{En la función de prestamista de última instancia}

Un banco central puede cumplir su función de prestamista de última instancia en dólares si tiene reservas liquidas suficientes en esa moneda. Pero de acuerdo con las normas vigentes, el Banco de la República no puede destinar las reservas internacionales para brindar liquidez en moneda extranjera al sistema financiero dolarizado ante una corrida bancaria o una caída de la liquidez.

Por ello, con el fin de tener una fuente de liquidez en moneda extranjera, el banco central o el gobierno nacional deberían crear un fondo de liquidez. Obtener recursos y mantenerlos disponibles puede resultar en un costo fiscal, al tiempo que se da un subsidio a los intermediarios financieros, que tendrían incentivos para tomar riesgos cambiarios excesivos. 
Una alternativa sería imponer requisitos de encaje más altos a los depósitos en moneda extranjera. Esto podría encarecer el crédito y disminuir la remuneración de los depósitos en moneda extranjera.

\section{MEDICIÓN DEL RIESGO Y CAPITALIZACIÓN DE LOS INTERMEDIARIOS FINANCIEROS}

No basta aplicar los pilares del Acuerdo de Capital de Basilea. Si bien la responsabilidad de la administración de riesgos recae directamente en las instituciones financieras, un ambiente dolarizado requiere que la supervisión asegure que los bancos administran adecuadamente todos sus riesgos, incluidos el riesgo crediticio de los préstamos en dólares y los riesgos de liquidez de origen sistémico.

Los requerimientos de capital mínimo y las provisiones de cartera se deben evaluar de tal forma que se tenga un respaldo suficiente para proteger la solvencia de las instituciones financieras en un ambiente dolarizado. A su vez, se deben revaluar los estándares mínimos de liquidez y las medidas para proporcionar liquidez.

\section{CONCLUSIONES}

Gracias a que la economía colombiana tiene una moneda y una autoridad monetaria creíbles, y a que se tamaño es mediano y su grado de integración con el exterior no se ha manifestado en tipo alguno de dolarización, y dada la posibilidad que hoy tienen los agentes de mantener activos y pasivos en moneda extranjera, los beneficios potenciales de la dolarización financiera se limitan a una mayor eficiencia y a una reducción de costos de transacción con el exterior.

En cambio, los costos de la dolarización financiera, entre ellos una mayor vulnerabilidad de la economía, y los efectos sobre la credibilidad y la autonomía de la autoridad monetaria, serían cuantiosos, especialmente si se comparan con los beneficios potenciales, como se muestra en el cuadro 6.

Por las razones expuestas, y con base en la revisión de la literatura y la experiencia internacional sobre los determinantes y consecuencias de la dolarización financiera, encontramos que la dolarización no responde a las características y necesidades de la economía colombiana. 


\section{Cuadro 6}

Efectos de las consecuencias de la dolarización financiera en Colombia

\begin{tabular}{|c|c|c|c|}
\hline \multirow{2}{*}{ Consecuencia } & \multicolumn{3}{|c|}{ Efecto } \\
\hline & Positivo & Negativo & Inocuo \\
\hline Dólar como alternativa de reserva de valor & ** & & \\
\hline Profundización del sistema financiero & & & $* *$ \\
\hline Costos de transacción y cobertura natural & * & & \\
\hline Impacto en el nivel de riesgo sistémico & & $*$ & \\
\hline Función de prestamista de última instancia & & $*$ & \\
\hline Función de supervisión del sector financiero & & * & \\
\hline Política cambiaria y monetaria & & $*$ & \\
\hline Reputación y credibilidad del banco central & & * & \\
\hline Impacto en el financiamiento local & & *** & \\
\hline Persistencia de la dolarización & & $* *$ & \\
\hline
\end{tabular}

\section{ANEXO}

\section{LA EXPERIENCIA DE PERÚ Y CHILE CON LA DOLARIZACIÓN}

\section{El CASO de PERÚ ${ }^{27}$}

E1 recorrido de la dolarización en Perú: en 1991, luego de la hiperinflación de 1990, la dolarización financiera ascendió al 60\%, y se ha mantenido entre el 65\% y el 70\% durante los noventa. Desde 2000 la dolarización financiera se ha reducido constante y lentamente.

El proceso de desdolarización obedeció a que: i) en 1994 empezó a anunciar objetivos de inflación, pero enmarcados en un régimen de metas monetarias; ii) en 2002 anunció la adopción de un régimen de inflación objetivo, que redujo la inflación y la volatilidad de la tasa de interés, y iii) entre 2001 y 2006 se produjo una apreciación real y nominal del nuevo sol, que desincentivó los depósitos en moneda extranjera.

Además, se han identificado algunas presiones 'internacionales' para la desdolarización (Honohan, 2007): i) depreciación del dólar y disminución de la dolarización deseada; ii) depreciación del dólar y caída del valor de los depósitos en dólares como porcentaje de los depósitos totales, y iii) efecto demostración: la dolarización financiera en Argentina terminó en un congelamiento de depósitos y una conversión forzada de los depósitos; la dolarización financiera no es garantía per se de reserva de valor.

Actualmente, la conducción de la política monetaria presenta algunos patrones de una economía no dolarizada. Se destaca la baja variabilidad de la tasa de interés en comparación con otros países con metas de inflación.

No obstante, la variabilidad del tipo de cambio nominal es relativamente baja, en parte por las intervenciones en el mercado cambiario.

Si bien la utilización de un esquema completo de metas explícitas de inflación ha sido en general exitoso, Perú aún mantiene características de una economía dolarizada, como el temor a la flotación.

${ }^{27}$ Con base en Castillo y Winkelried (2007) y Leiderman et al. (2006). 


\section{Gráfica 8}

Volatilidad de las reservas internacionales

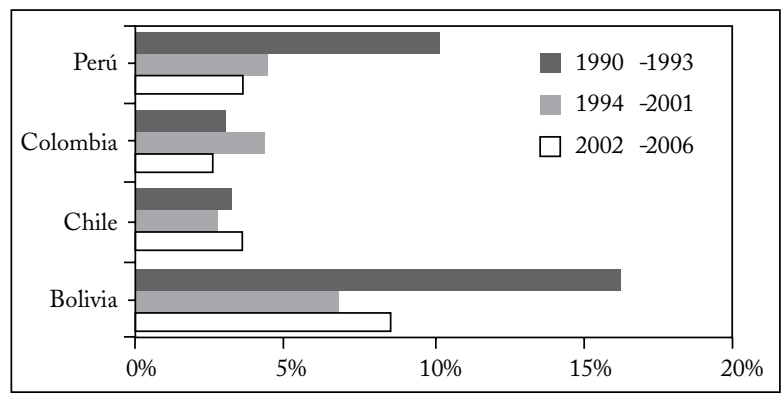

Fuente: IFS, y FMI.

\section{El CASO DE CHILE ${ }^{28}$}

Chile es un ejemplo de un país que desdolarizó con éxito su sistema financiero a comienzos de los sesenta y evitó la dolarización en las décadas siguientes. El recorrido de la dolarización en Chile:

- 1959-1961: desregulación de la economía, inflación moderada e incentivos regulatorios para hacer depósitos en dólares.

- Octubre de 1962: crisis de balanza de pagos, abandono del tipo de cambio fijo, efecto balance y desdolarización forzada experiencia negativa con la dolarización financiera.

- Década de 1960: indexación de la economía (préstamos, depósitos, bonos de deuda pública). Primero se indexó al IPC, luego a la unidad de fomento -UF- (1967). En 1972 más del 90\% de los ahorros financieros estaban indexados, así como el salario mínimo y las pensiones.

- 1975-1981: nueva desregulación, inflación moderada y reducción de la indexación de los ahorros financieros al 45\%. Las altas tasas de interés en moneda local y las restricciones a la intermediación en moneda extranjera explican que la dolarización no haya aumentado de manera exagerada.

- 1982-1984: la tasa de cambio se devaluó fuertemente en 1982 (40\% en septiembre). Las autoridades económicas propiciaron un aumento de la indexación a la UF por encima del 70\% de los ahorros financieros, evitando la dolarización ${ }^{29}$.

- 1985-2001: la indexación se mantuvo alrededor del 70\% de los ahorros financieros. La dolarización fue limitada e incluso decayó en algunos periodos por los controles a los flujos de capital y los diferenciales de tasas de interés. Las autoridades buscan desindexar (nominalizar) la economía.

${ }^{28}$ Con base en Herrera y Valdés (2004).

${ }^{29}$ Las autoridades económicas propiciaron el uso de la UF como unidad de cuenta de las transacciones financieras, inclusive ejecutando la política monetaria a través de la tasa de interés en UF. A esto se une que ya se usara para denominar salarios, pensiones y otros precios (indexación real). 
- 2001: el banco central, en un esfuerzo por nominalizar la economía, deja de conducir la política monetaria mediante las tasas de interés en UF. La indexación empieza a ceder, con cerca del 50\% de los depósitos y un 35\% de los créditos en pesos.

Gráfica 9

Chile: Composición de los depósitos y captaciones a más de 30 días

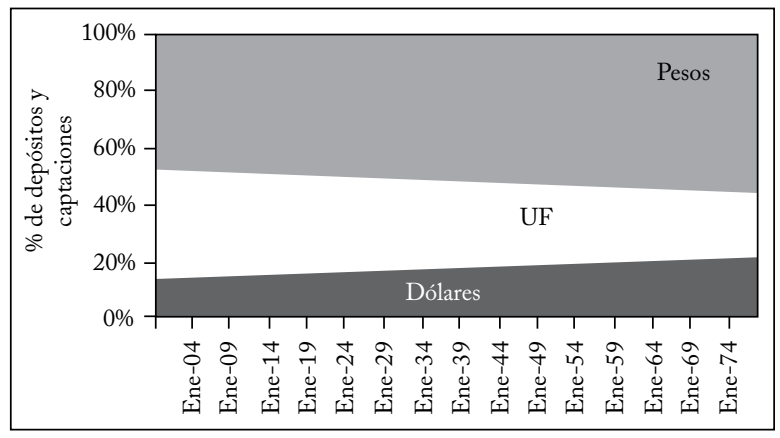

Fuente: Herrera y Valdés (2004).

Razones por las cuales Chile no se dolarizó: i) 1959-61: desregulación de la economía, inflación moderada e incentivos regulatorios para hacer depósitos en dólares; ii) se utilizó la indexación para evitar la dolarización. En vez de sustituir la moneda local por la extranjera, se sustituyó por la UF, que goza de credibilidad y confianza del público; iii) desde 1976 el público confía en la política fiscal, lo que ha ayudado a que confíe en la indexación, y iv) malas experiencias pasadas (1959-1962) con la dolarización.

\section{REFERENCIAS BIBLIOGRÁFICAS}

1. Barajas, A. y A. Morales. "Dollarization of Liabilities: Beyond the Usual Suspects”, IMF Working Paper WP/03/11, 2003.

2. Berg, A. y E. Borensztein. "The Pros and Cons of Full Dollarization", IMF Working Paper WP/00/50, 2000.

3. Berkmen, P. y E. Cavallo. "Exchange Rate Policy and Liability Dollarization: An Empirical Study", IMF Working Paper WP/07/33, 2007.

4. BID. "Causas y consecuencias de la dolarización financiera", Desencadenar el crédito: como ampliar y estabilizar la banca, Washington, 2004.

5. Bordo, M.; C. Meissner y A. Redish. "How 'Original Sin' was Overcome: The Evolution of External Debt Denominated in Domestic Currencies in the United States and the British Dominions 18002000”, NBER Working Paper 9841, 2003.

6. Calvo, G. y C. Reinhart. "Fear of Floating", Quarterly Journal of Economics 117, 2, 2002, pp. 379-408.

7. Calvo, G.; A. Izquierdo y L. Mejía. "On the Empirics of Sudden Stops: The Relevance of Balance-Sheet Effects", NBER Working Paper 10520, 2004. 
8. Castillo, P. y D. Winkelried. "Dollarization Persistent and Individual Heterogeneity", Documentos de Trabajo del Banco Central de Reserva del Perú 2007-004, 2007.

9. Catao, L. y M. Terrones. "Determinants of Dollarization: The Banking Side”, IMF Working Paper WP/00/146, 2000.

10. Cayazzo, J.; P. García; E. Gutiérrez y S. Heysen. “Toward an Effective Supervisión of Partially Dollarized Banking Systems", IMF Working Paper WP/06/32, 2006.

11. De Brun, J. y G. Lisandro. "Regreso del infierno. Manejo de la crisis en una economía dolarizada: el caso de Uruguay”, Dolarización financiera: la agenda de politica, Lima, FMI y Banco Central de Reserva del Perú, 2006.

12. De Nicoló, G.; P. Honohan y A. Ize. "Dollarization of the Banking System: Good or Bad?”, Policy Research Working Paper 3116, 2003.

13. Dornbusch, R.; S. Fischer y R. Startz. Macroeconomics, New York, McGraw Hill e Irwin, 2003.

14. Eichengreen, B. "Crisis, Prevention and Management: Any New Lessons from Argentina and Turkey?", mimeo, 2001.

15. Ganapolsky, E. "Optimal Fear of Floating: The Role of Currency Mismatches and Fiscal Constraints", Federal Reserve Bank of Atlanta Working Paper Series 2003-31, 2003.

16. Gómez, J. "La dolarización parcial y la efectividad de la política monetaria”, Banco de la República de Colombia, mimeo, 2007.

17. Gosh, A. et al. "Does the Exchange Rate Regime Matter for Inflation and Growth", Economic Issues 2, 1996.

18. Gulde, A. et al. "Dealing with Banking Crises in Dollarized Economies", IMF Occasional Paper 217, 2003.

19. Hererra, L. y R. Valdés. "Dedollarization, Indexation and Nominalization: The Chilean Experience", Documentos de Trabajo del Banco Central de Chile 261, 2004.

20. Heysen, S. "Dollarization: Controlling Risk is Key", Finance and Development, Washington, IMF, 2005.

21. Honig, A. "Fear of Floating and Domestic Liability Dollarization", Emerging Markets Review 6, 3, 2005, pp. 289-307.

22. Honohan, P. y A. Shi. "Deposit Dollarization and the Financial Sector in Emerging Economies", Policy Research Working Paper 2748, 2001.

23. Honohan, P. "Dollarization and Exchange Rate Fluctuation", IIIS Discussion Paper 201, 2007.

24. Ize, A. "Implicancias de la dolarización parcial para el régimen de metas de inflación: Un análisis basado en la literatura sobre la dolarización”, Dolarización financiera: la agenda de politica, Lima, FMI y Banco Central de Reserva del Perú, 2006.

25. Ize, A. y E. Levy. "Dollarization of Financial Intermediation: Causes and Policy Implications", IMF Working Paper WP/98/28, 1998.

26. Ize, A. y E. Levy. "Financial De-Dollarization: Is it for Real?", Documento de Trabajo 05, Centro de Investigación en Finanzas, Universidad Torcuato Di Tella, 2005. 
27. Ize, A. y E. Parrado. "Dollarization, Monetary Policy and PassThrough", IMF Working Paper WP/01/188, 2002.

28. Ize, A.; M. Kiguel y E. Levy. "E1 manejo de riesgo de liquidez sistémico en economía con dolarización financiera”, Dolarización financiera: la agenda de politica, Lima, FMI y Banco Central de Reserva del Perú, 2006.

29. Kaminsky, G. y C. Reinhart. “The Twin Crises: The Causes of Banking and Balance-of-Payments Problems", American Economic Review 89, 3, 1999, pp. 473-500.

30. Leiderman, L.; R. Maino y E. Parrado. "Metas de inflación en economías dolarizadas", Dolarización financiera: la agenda de politica, Lima, FMI y Banco Central de Reserva del Perú, 2006.

31. Rennhack, R. y M. Nozaki. "Financial Dollarization in Latin America", IMF Working Paper 06/7, 2006.

32. Rojas-Suárez, L. y S. Weisbrod. "Las crisis bancarias en América Latina: experiencias y temas", Las crisis bancarias en América Latina, Washington, BID, 1997.

33. Sachs, J. y F. Larrain. "Why Dollarization Is More Straitjacket Than Salvation", Foreign Policy, fall, 1999.

34. Savastano, M. "Dollarization in Latin America. Recent Evidence and some Policy Issues”, P. Mizen y E. Pentecost, eds., The Macroeconomis of International Currencies: Theory, Policy, Evidence, Cheltenham, Edward Elgar, 1996.

35. Sierra, E. y O. Padilla. "Alternativas de dolarización, convertibilidad y políticas monetarias en el marco actual del Ecuador", A. Acosta y J. Juncosa, eds., Dolarización: informe urgente, Quito, ILDIS, 2000.

36. Singh, A. et al. "Stabilization and Reform in Latin America: A Macroeconomic Perspective on the Experience since the Early 1990s", IMF Occasional Paper 238, 2005.

37. Turner, P. "Descalces de monedas y dolarización de pasivos locales", Dolarización financiera: la agenda de politica, Lima, FMI y Banco Central de Reserva del Perú, 2006. 